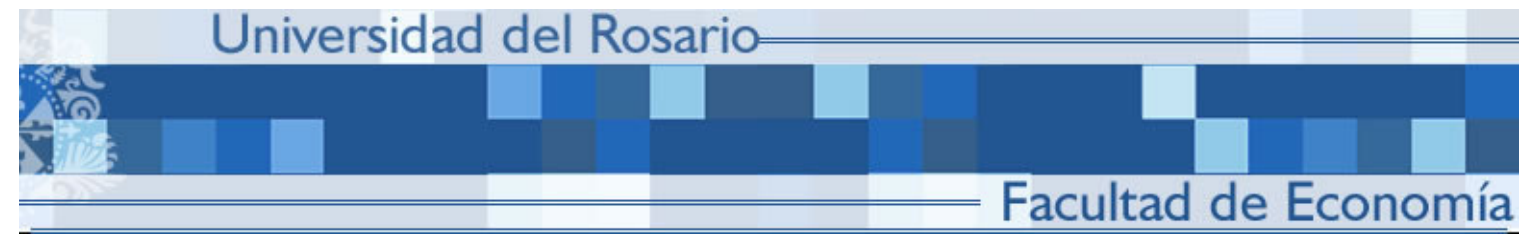

Determinants of demand for antenatal care in Colombia

Andrés Vecino Ortiz

SERIE DOCUMENTOS DE TRABAJO

No. 22

Septiembre 2007 


\title{
Determinants of demand for antenatal care in Colombia*
}

\author{
Andrés I. Vecino Ortiz ${ }^{1}$
}

\begin{abstract}
Even though antenatal care is universally regarded as important, determinants of demand for antenatal care have not been widely studied. Evidence concerning which and how socioeconomic conditions influence whether a pregnant woman attends or not at least one antenatal consultation or how these factors affect the absences to antenatal consultations is very limited. In order to generate this evidence, a two-stage analysis was performed with data from the Demographic and Health Survey carried out by Profamilia in Colombia during 2005. The first stage was run as a logit model showing the marginal effects on the probability of attending the first visit and an ordinary least squares model was performed for the second stage. It was found that mothers living in the pacific region as well as young mothers seem to have a lower probability of attending the first visit but these factors are not related to the number of absences to antenatal consultation once the first visit has been achieved. The effect of health insurance was surprising because of the differing effects that the health insurers showed. Some familiar and personal conditions such as willingness to have the last children and number of previous children, demonstrated to be important in the determination of demand. The effect of mother's educational attainment was proved as important whereas the father's educational achievement was not. This paper provides some elements for policy making in order to increase the demand inducement of antenatal care, as well as stimulating research on demand for specific issues on health.
\end{abstract}

Keywords: antenatal care, health care demand

\footnotetext{
* Versión final publicada en Health Policy 86 (2008), 363-372

${ }^{1}$ Young researcher, School of Economics. Universidad del Rosario

Cl $14 \mathrm{~N}^{\circ}$ 4-69 Bogotá D.C., Colombia

E-mail: andres.vecino@gmail.com
} 


\section{Introduction}

\subsection{A bit of antenatal care history and overview}

John William Ballantyne was a gynaecologist from Edinburgh University who worked on pregnancy diseases and their effects on the health of newborns and their mothers. In the first years of the $20^{\text {th }}$ century, he called the attention on high perinatal and maternal mortality rates and he considered it was consequence of poor control during pregnancy and labour. Ballantyne designed the first "guidelines" for antenatal care and some of these basic concepts are still being applied. Nonetheless, the World Health Organization has made efforts to take antenatal care guidelines to the evidence-based medicine level. In 1989, Cochrane stated that "By some curious chance, antenatal care has escaped the critical assessment to which most screening procedures have been subjected". This lack of evidence and guidelines establishing which interventions are efficient is inadequate in the sense that excessive visits or unnecessary screening tests represent costs for health systems and women, discouraging them from using the services and similarly, interventions which might be of key importance may be ignored.

Despite the fact that evidence regarding some specific aspects of antenatal care has not been completely developed, antenatal care as a whole has proved to be of key importance in reducing maternal and child mortality. However, evidence assessing the determinants of antenatal care demand is not available.

\subsection{The Colombian health system}

Health care in Colombia was designed as an insurance-based system since the health reform of 1993. The health reform created two types of health insurance with different benefit packages known as Contributory and Subsidized regimens. The Contributory Regimen is constituted by people who have formal employment or payment-capacity. In this regimen, enrolees and enterprises disburse a percentage (4\% and $8.5 \%$, respectively) of the worker's monthly wage to the EPS (insurers of Contributory Regimen); the EPS addresses those resources to an equalization fund called Fosyga, created with the aim of distributing these resources. This fund then drives back an annual premium to the EPS according to the epidemiologic profile of its enrolees (discriminated exclusively by age, sex and region where they live). Users are able to extend the insurance to their parents or children. 
On the other hand, the Subsidized Regimen was designed in order to ensure health coverage for people with no payment capacity. In order to identify the poor population, a household questionnaire with a six-level scale called SISBEN was developed. Households classified on $1^{\text {st }}$ or $2^{\text {nd }}$ level (considered poor) are eligible to receive total subsidies to health insurance paid by local governments. Urban households on the $3^{\text {rd }}$ level receive a partial health-subsidy and subject to availability, they may be eligible for total subsidy. Local governments contract with ARS (insurers of Subsidized Regimen), maximizing the number of affiliated households subject to their budget restriction, which is composed by transfers coming from Central Government and local public spending. Central government disburses an annual amount known as transfers whereas local public spending is afforded with taxes from alcoholic drinks selling, lotteries and gambling and royalties from oil extraction. Moreover, Fosyga saves an amount equal to $1.5 \%$ of the Contributory regimen enrolee's monthly wage, which is set aside for insuring poor people in the subsidized regimen. The local government pays a premium to a Subsidized Regimen Stakeholder (ARS) which ensures health insurance for households classified on $1^{\text {st }}$ and $2^{\text {nd }}$ level and total or partial subsidies for those located on the $3^{\text {rd }}$ level. According to law, affiliation to ARS must be made in strictly increasing order of SISBEN level

The Subsidized Regimen has a smaller medical benefit package than the Contributory one which means fewer services provided by insurers (ARS). Financing of the health system is divided into two groups, demand and supply-driven resources. The first one involves Contributory and Subsidized regimens. Supply-driven resources comprised a remnant strategy to ensure health care attention during the transition from the earlier National Health System to the current Health Insurance System for those who were not insured at the time of requiring health care. Supply-driven resources were supposed to be finished by 2001 when global coverage was achieved. However, this never happened and supply-driven resources have been kept until now. Uninsured poor people are covered by local governments in primary care interventions, high-level attention of medical care and some items of intermediate-level attention.

Differences on quality among Contributory, Subsidized and uninsured population have been speculated but rigorous research in this field has not been developed. 


\subsection{Antenatal health care guidelines}

Since 2000, the Ministry of Health in Colombia established guidelines for several interventions on public health known as Resolución 412 de 2000. Among other interventions, antenatal care was included within this statement. These regulations attempted to standardize clinical procedures of antenatal care in Colombia, which is an intervention defined as "Public health procedure of compulsory demand inducement and realization". Those who are insured under Contributory or Subsidized regimens must receive antenatal care from their health insurers whereas health care attention of uninsured women must take place at public hospitals and is afforded by local governments. In addition, Resolución 3384 de 2000 stated that antenatal care is exempt of copayments.

According to law, the first antenatal consultation must be with a medical doctor and further consultations must be performed by a medical doctor or a professional nurse, at least once per month since pregnancy diagnosis and until the $36^{\text {th }}$ week. Further antenatal consultations will take place every two weeks until giving birth.

\subsection{Two-part model of health care demand}

Models of health care demand have evolved from a one part perspective towards a twopart. The first type of model was used by Grossman (1972) focusing in an intertemporal utility maximization where health is considered as a commodity which has an inherited stock and undergoes investments and depreciation. Later, other researches have been concerned because determinants of the first visit and further might be different, partly because of the agency problem in terms of the demand inducement. In these models, the patient takes the decision of attending the first medical visit but further consultations are decided by both patient and medical doctor where each one maximizes his utility function and takes advantage of some information asymmetry problems. To overcome this issue, the two part model on health care demand has been widely used. Several authors have used this interesting model with small differences on the statistical methods. Duan and Manning (1981) developed a two part model with a first probit stage and then a second log-linear stage. Pohlmeier and Ulrich (1995) and Cameron and 
Trivedi (1998) employed the "hurdle" model which uses a probit and then a negative binomial "hurdle" model.

Other papers have modelled the second stage with ordinary least squares such as Hurd and McGarry (1995), Beeuwkes and Zaslavsky (2003) and (Mullahy, 1997) taking into account that variables which determine the first contact with medical doctor (or for instance, first contact with drugs in the case of substance abuse studies) shape in a different way additional contacts.

\section{Methods}

The aim of this study was to find the determinants of demand for antenatal care in Colombia. For this purpose, data regarding environment, health insurance, financing, personal information and relevant gynaecological history of 1282 mothers who gave birth to their last child between 1999 and 2005 was extracted from the national Demographic and Health Survey (DHS) developed in 2005 by Profamilia.

The first group of independent variables comprises environmental data and includes variables regarding the region ${ }^{2}$ of the country such as:

Caribbean region (Atlántico, Bolívar, Cesar, Córdoba, Guajira, Magdalena, Sucre and San Andrés y Providencia), Eastern region (Boyacá, Cundinamarca, Meta, Norte de Santander, Santander), Central region (Antioquia, Caldas, Caquetá, Huila, Quindío, Risaralda, Tolima), Pacific Ocean region (Cauca, Chocó, Nariño and Valle del Cauca), Bogotá and Orinoco river and Amazonas region (Arauca, Casanare, Putumayo, Amazonas, Guainía, Guaviare, Vaupés, Vichada). Other variables related to environment comprise area of residence (urban or rural) and time of residence (time in months the mother lived in that place before giving birth to this child). This variable was used in order to make a proxy for social network and knowledge and confidence with the local environment. When the mother changed her area of residence after having the last child or when she had not ever moved, the mother received an input of 62 months, which is the maximum observed value for this variable. People living in the household is a variable which accounts for number of people living at home although unfortunately, it was not possible to discern family composition by age. Finally, logarithm of wealth was calculated by means of component principal analysis.

\footnotetext{
${ }^{2}$ Administrative division in Colombia comprises 32 departments and one district (Distrito Capital, Bogotá) clustered in six geographic regions.
} 
The second group of independent variables is related to health insurance and attention. Dummy variables described the mother's health insurance in the following categories: EPS, ARS or uninsured (vinculado).

Personal information variables start with stable union, which obtains a value 1 if the mother is married or has a stable unmarried union and 0 if she is separated, widow or single. Mother's years of education is a continuous variable which takes values from 0 to 18. Literacy is a dummy variable which is given a value of 1 if she is literate and of 0 if she is functionally or structurally illiterate. Non-willingness is a variable which accounts for time in months that the mother wanted to delay this birth. When a mother desired to have the child in the same moment she actually had, she received a zerovalue, while a 132 value was assigned when the mother did not wish to have this child at all. Father's years of education is analogous to the variable described for the mother.

Gynaecological history is the last category. In this set four variables were defined. Age of delivery is the age at the time of this birth. Time since the last pregnancy loss is a variable which measures the time in months since the last abortion. Those women who did not have history of abortions before this birth are assigned a zero. Multiple pregnancy is a dummy variable constructed in order to characterize multiple births. This variable captures a set of pregnancies classified as "high risk pregnancies". Number of children is a continuous variable which accounts for all living children that this mother has, including this birth. Explanatory variables and description are given in Table 1.

A two-part model to explain demand for antenatal care was defined. The first part comprises variables related to first contact for antenatal care which was run as a logit regression.

The first stage of the model is represented by the following logit regression for mothers $i$ and households $h$ :

$$
\hat{Y} c_{i h}=\operatorname{Pr}\left(\text { Any consult }_{\text {ih }}=1\right)=F\left(\beta_{1} \mathrm{E}_{\mathrm{h}}, \beta_{2} \mathrm{I}_{\mathrm{ih}}, \beta_{3} \mathrm{P}_{\mathrm{ih}}, \beta_{4} \mathrm{G}_{\mathrm{ih}}\right)
$$

Where $\hat{Y} c_{i h}$ is the dummy dependent variable which estimates the probability of a mother to attend to at least one medical antenatal visit. $\bar{E}_{h}$ is the set of environmental variables, $\bar{I}_{i h}$ are dummy variables related to health insurance (EPS, ARS), $\bar{P}_{i h}$ is the set of personal information variables, $\bar{G}_{i h}$ are explanatory variables for relevant 
gynaecological history and $\mathrm{F}$ is the logit function. Each antenatal consultation was defined in this paper as "medical consultation" when a medical doctor or professional nurse was in charge of it. Otherwise, all other visits (for instance to midwifes) were considered non-medical consultations.

As this dependent variable was constructed as a dummy, the meaning of its values is:

0: She did not undergo an initial consultation or if she did, she attended at least one nonmedical antenatal consultation.

1: She assisted at least to one medical antenatal consultation with a medical doctor or a professional nurse (as established by law).

In 15 cases, mothers attended both medical and non-medical consultations. As it was not possible to discern how many times they attended each type of consultation, they were assigned a zero-value in the dependent variable.

The second part of the model explains the determinants of further consultations in function of the number of absences, given that this group of women attended at least one consultation. This dependent variable was defined as the difference between the number of consultations she should have undergone and the number of consultations she actually assisted. This implies that, the closer this variable is to zero, the closer this mother is of achieving all required antenatal consultations.

The second dependent variable was modelled as

$$
Y a_{i h}=E C_{\text {ih }}-\mathrm{PC}_{\mathrm{ih}} ; Y a_{i h} \geq 0
$$

For mothers $i$ and households $h$.

Where $Y a$ are the absences to antenatal care consultation, $E C_{i h}$ are consultations that each woman should attend (according to her pregnancy duration) and $P C_{i h}$ consultations she actually assisted. When antenatal care visits are more than consultations expected, a zero-value was inputted. Table 4 shows descriptive statistics of dependent variables. 
The second stage of the model is defined for mothers $i$ and households $h$ :

$$
\begin{aligned}
& \hat{Y} a_{i h}=E\left(\text { Number of absences }_{i h} \mid Y c_{i h}=1\right)=\alpha_{a}+\beta_{5} \mathrm{E}_{\mathrm{h}}+\beta_{6} \mathrm{I}_{\mathrm{ih}}+\beta_{7} \mathrm{P}_{\mathrm{ih}}+ \\
& +\beta_{8} \mathrm{G}_{\text {ih }}+\beta_{9} \mathrm{~F}_{\mathrm{ih}}+\mu_{\mathrm{a}}
\end{aligned}
$$

Where besides previous variables, $\hat{Y} a_{i h}$ is a dependent variable which accounts for the estimated absences to antenatal care attention during this pregnancy. Moreover a new

vector $\bar{F}_{i h}$ was added to characterize the type of financing which this antenatal consultation was afforded with. $\mu_{a}$ is the error term for this linear regression. The distribution of absences is showed in Figure 1.

\section{Results}

Descriptive statistics are summarized in tables 2 and 3. and data from models regression are shown in Table 5.

Regarding the importance of region in the antenatal care attention, mothers living in the Pacific Region showed a smaller probability of assisting to the first visit when compared with Bogotá $(\mathrm{p}=0.028)$. The Pacific region is the poorest region of Colombia and problems of corruption and a profound lack of institutionality as well as the poor infrastructure and access to public and health services have been revealed. Area (urban or rural) and time in months living in the same place (time of residence) seemed not to be important in determining demand for antenatal care. Number of people living in the household had a decreasing and convex effect on the probability of the first consultation but it did not have effect in further visits.

Wealth demonstrated to be related to the first and further visits. Health insurance variables revealed that affiliation to an ARS is related to a greater chance of attending the first visit with respect to those uninsured $(\mathrm{p}=0.043)$ while the effect related to EPS was observed to be not significant. Interestingly, despite the fact that being insured to an EPS is not related with attending the first consultation at a $5 \%$ confidence level, when absences were observed EPS had a strong effect in avoiding absences while ARS did not. Antenatal care afforded with demand resources demonstrated to have a positive effect in the number of consultations with respect to out of pocket payment category. Supply resources had the same effect $(\mathrm{p}=0.077)$.

Mothers who were married or had a stable unmarried union attended the first visit with a greater chance than single mothers; however, this fact did not affect further visits at 
all. Mother's years of education had a strong positive effect in both first visit and further consultations. Father's years of education seemed not to be related in either attending at least one visit or further visits. Literacy was not a determinant of antenatal care demand whereas non-willingness to have this child demonstrated to increase the number of absences $(\mathrm{p}=0.065)$.

Age of delivery was a relevant variable only in determining the first visit. This confirms the intuitive thesis that older mothers have a higher probability of attending the first visit. Time since the last pregnancy loss had an interesting effect because, although this is a result at a $10 \%$ significance level $(\mathrm{p}=0.055)$, this variable was related to an increased probability of absences. Multiple pregnancy was an important factor which increased the number of consultations, probably because multiple pregnancies have a greater demand inducement since they are considered as "high-risk pregnancy". Number of children was strongly related in both parts with a small probability of visit.

\section{Discussion}

Several interesting points deserve to be highlighted. The absence of effect of area (either, urban or rural) was surprising and indicates that problems of access are determined by region as a whole instead of the specific location within that region (urban or rural).

Regarding wealth, it is clear that wealthier mothers have more chance of attending a first visit and additional visits than poorer. More interesting is to note that enrolment in an ARS is related to a greater chance of attending the first antenatal visit while enrolment in an EPS does not have this relationship. Nonetheless, further consultations are strongly related with health insurance provided by an EPS whereas ARS have not effect. It was found that affording antenatal care with demand resources as a whole, increase the chance of visits more than those mothers who afford antenatal care with out-of-pocket payments and even than those uninsured mothers whose antenatal care visits are afforded with supply resources.

Mothers married or having a stable union seem to be more likely to assist to a first antenatal consultation and further visits.

Mother's educational attainment was a very important determinant on demand for antenatal care while father's educational attainment had no effect which is consistent with other studies in maternal and child health. (Gaviria, 2006). 
It was surprising to find no effect of literacy per se, without the effect captured by mother's educational attainment. Age of delivery has a linear positive relationship with the probability of attending the first consultation, which reflects the effect of maturation.

\section{Conclusions and recommendations}

This paper provides elements for policy making in maternal and child health care. The social network around the mother shows to be important when measured indirectly with some variables such as people living in the household, stable union or number of children (assuming the opportunity cost of attending one visit in terms of taking care of her children).

Wealth per se has a strong effect perhaps because of labour issues in the sense of the opportunity cost of attending one visit instead of working, access to clinical facilities (because of both, distance to clinical facility and the cost of getting there). Health insurance is a very interesting point because although ARS induce demand for first visit more strongly than EPS do, ARS seem to follow up the mothers in an inadequate way, so that at a 95\% confidence level, ARS does not achieve a significant difference on number of consultations when compared with uninsured women. Educational attainment of the mother is fundamental in determining the demand for antenatal care as in other health issues (Gaviria, 2006) whereas literacy is not relevant in taking the decision of attending antenatal care. The effect of having a job at the time of pregnancy was not assessed because the variable was not available in the questionnaire. The quantification and qualification of job of the mother during this period is strongly suggested.

\section{Acknowledgements}

To Ramón Abel Castaño, Carolina Lopera, Manuel Ramírez, Isabel Rodríguez y Andrés Zambrano for their invaluable comments. 


\section{References}

Beeuwkes M, Zaslavsky A. Too much ado about two-part models and transformation? Comparing methods of modeling Medicare expenditures. Journal of Health Economics. 2004; $23: 525-42$

Duan N, Manning W, Morris C, Newhouse J. A comparison of alternative models for the demand for medical care. Journal of Business \& Economics Statistics. 1983; 1 (2): $115-126$

Gaviria A, Palau M. Nutrición y salud infantil en Colombia: determinantes y alternativas de política. Working paper. CEDE, Centro de Estudios de Desarrollo Económico. Abril, 2006

Grossman M. On the concept of health capital and the demand for health. The Journal of Political Economy. 1972; 80 (2): 223-55

Ho K. Insurer provider networks in the medical care market. NBER, National Bureau of Economic Research. 2004; working paper 11822.

Available in URL:http://www.nber.org/papers/w11822

Hurd M, McGarry K. Medical insurance and the use of health care services by the elderly. Journal of Health Economics. 1997; 16: 129-54

King E, Hill A. Women's Education in Developing Countries: barriers, benefits, and policies. Comparative Education. 1995; 31 (1): 123-4

McCrary J, Royer H. The effect of female education on fertility and infant health: evidence from school entry policies using exact date of birth. NBER, National Bureau of Economic Research. 2004; working paper 12329.

Available in URL:http://www.nber.org/papers/w12329 
Miilunpalo S, Vuori I, Oja P, Pasanen M, Urponen H.Self-rated health status as a health measure: the predictive value of self-reported health status on the use of physician services and on mortality in the working-age population. Journal of Clinical Epidemiology. 1007; 50 (5): 517-28

Miller G. Contraception as development? New evidence from family planning in Colombia. NBER, National Bureau of Economic Research. 1998; working paper 11704. Available in URL:http://www.nber.org/papers/w11704

Mullahy J. Much ado about two: reconsidering retransformation and the two-part model in health econometrics. NBER, National Bureau of Economic Research. 1998; technical working paper 228

Available in URL: http://www.nber.org/papers/T0228

Nelder JA, Wedderburn WM. Generalized linear models. Journal of the Royal Statistical Society. Series A (General). 1972; 135 (3): 370-84

Pohlmeier W, Ulrich V. An econometric model of the two-part decisionmaking process in the demand for health care. Journal of Human Resources. 1995; 30 (2): 339-61

Ramaswamy V, Anderson E. DeSarbo W. A disaggregate negative binomial regression procedure for count data analysis. Management Science. 1994; 40 (3): 405-17

Trías J. Determinantes de la utilización de los servicios de salud: el caso de los niños en la Argentina. Working paper $\mathrm{N}^{\circ}$ 9. CEDLAS, Centro de Estudios, Distributivos, Laborales y Sociales. May, 2004

Available in URL: https://www.depeco.econo.unlp.edu.ar/cedlas/pdfs/doc_cedlas9.pdf

Warner G. Prenatal care demand and birthweight production of black mothers. The American Economic Review. 1995; 85 (2): 132-7

Wooldridge. Introductory Econometrics: A modern approach. Mason: Ohio; 2003. 


\section{Tables and figures}

Table 1. Design of independent variables

\begin{tabular}{|c|c|c|}
\hline Variable & Description or question & Values \\
\hline \multicolumn{3}{|l|}{ Environment } \\
\hline Caribbean region & \multirow{5}{*}{ In which region does this mother live? } & $1=$ Yes, $0=$ Otherwise \\
\hline Eastern region & & $1=$ Yes, $0=$ Otherwise \\
\hline Central region & & $1=$ Yes, $0=$ Otherwise \\
\hline Pacific Ocean region & & $1=$ Yes, $0=$ Otherwise \\
\hline Orinoco river region and Amazonas & & $1=$ Yes, $0=$ Otherwise \\
\hline Bogotá D.C.* & & $1=$ Yes, $0=$ Otherwise \\
\hline Area & Does this mother live in a urban or rural area? & $1=$ Urban, $0=$ Rural \\
\hline Time of residence & $\begin{array}{l}\text { Years living in this place until the birth of this } \\
\text { child }\end{array}$ & Number of years \\
\hline People living in the household & How many people live in this household? & Number of people \\
\hline Logarithm of wealth & $\begin{array}{l}\text { What is the logarithm of wealth of the mother's } \\
\text { household calculated by principal component } \\
\text { analysis? }\end{array}$ & $\begin{array}{l}\text { Logarithm of the value } \\
\text { obtained by means of } \\
\text { principal component } \\
\text { analysis }\end{array}$ \\
\hline \multicolumn{3}{|l|}{ Health insurance } \\
\hline EPS & Is this mother covered by an EPS? & $1=$ Yes, $0=$ Otherwise \\
\hline ARS & Is this mother covered by an ARS? & $1=$ Yes, $0=$ Otherwise \\
\hline Uninsured* & $\begin{array}{l}\text { Is this mother uncovered by any health } \\
\text { insurance institution? }\end{array}$ & $1=$ Yes, $0=$ Otherwise \\
\hline
\end{tabular}

\section{Financing}

Demand

Supply

Out of pocket*
Was the antenatal care for this child afforded by means of demand-driven resources?

Was the antenatal care for this child afforded by means of supply-driven resources?

Was the antenatal care for this child afforded by means of out of pocket payments?
$1=$ Yes, $0=$ Otherwise

$1=$ Yes, $0=$ Otherwise

$1=$ Yes, $0=$ Otherwise

Personal information

Stable union

Mother's years of education

Father's years of education

Literacy

Non-Willingness
Is this a child coming from a stable union (either married or unmarried) or coming from a single mother (single, widow, separated)?

Years of mother's education

Years of father's education

Is this mother literate?

How many months wanted this mother to delay this birth?
$1=$ Yes, $0=$ Otherwise

Number of years

Number of years

$1=$ Yes, $0=$ Otherwise

Number of months

Relevant gynaecological history

Age of delivery

Mother's age at birth

Number of years

Time since the last pregnancy loss

Multiple pregnancy

How many months ago this mother had a pregnancy loss?

Was this a multiple or a single pregnancy? $\quad 1=$ Multiple, $0=$ Single

Including this, how many alive children does this Number of children mother have?

including this

* Base group. Variable to which the groups of the variable are compared with. This is designed in order to measure the expected difference between each group of the variable and the base group. 
Table 2. Descriptive statistics of continuous independent variables

\begin{tabular}{lccccc}
\hline \multicolumn{1}{c}{ Variables } & Observations & Mean & $\begin{array}{c}\text { Standard } \\
\text { deviation }\end{array}$ & Minimum & Maximum \\
\hline Time of residence (months) & 1282 & 57.5982 & 6.9007 & 0 & 62 \\
People living in the household & 1282 & 4.3549 & 2.1148 & 1 & 17 \\
Logarithm of wealth & 1282 & 0.7465 & 0.5071 & 0 & 1.6094 \\
Mother's years of education & 1282 & 7.3182 & 4.3205 & 0 & 18 \\
Father's years of education & 1282 & 6.1450 & 4.9860 & 0 & 23 \\
Non-Willingness (months) & 1282 & 62.4266 & 61.0071 & 0 & 132 \\
Age of delivery (years) & 1258 & 29.2178 & 6.7998 & 14 & 47 \\
Time of pregnancy loss (months) & 1277 & 238.5027 & 88.1713 & 9 & 281 \\
Number of children & 1282 & 3.1677 & 2.0044 & 1 & 14 \\
\hline
\end{tabular}

Table 3. Descriptive statistics of dummy independent variables

\begin{tabular}{|c|c|c|c|}
\hline Variables & $\%$ & Variables & $\%$ \\
\hline Region & & Type of payment & \\
\hline Caribbean region & $17.82 \%$ & Demand & $61.79 \%$ \\
\hline Eastern region & $17.37 \%$ & Supply & $20.22 \%$ \\
\hline Central region & $23.67 \%$ & Out of pocket payment & $7.85 \%$ \\
\hline Pacific Ocean region & $19.59 \%$ & Marital status & \\
\hline Orinoco river region and Amazonas & $2.19 \%$ & Stable union & 28.08 \\
\hline Bogotá D.C. & $19.37 \%$ & Single mother & 71.92 \\
\hline Area & & Literacy & \\
\hline Urban & $77.84 \%$ & Literate & 84.66 \\
\hline Rural & $22.16 \%$ & Non-literate & 15.34 \\
\hline Health insurance & & Multiple pregnancy & \\
\hline EPS & $31.07 \%$ & Yes & $0.64 \%$ \\
\hline ARS & $34.34 \%$ & No & $99.36 \%$ \\
\hline Uninsured & $34.59 \%$ & & \\
\hline
\end{tabular}

Table 4. Descriptive statistics of dependent variables

\begin{tabular}{|c|c|c|}
\hline \multicolumn{2}{|c|}{ Variables } & $\%$ \\
\hline \multicolumn{3}{|c|}{ Attend first antenatal consultation } \\
\hline \multicolumn{2}{|c|}{$\begin{array}{l}\text { Yes, according to regulation (Medical doctor } \\
\text { and nurse with professional education) }\end{array}$} & $79.82 \%$ \\
\hline \multicolumn{2}{|c|}{$\begin{array}{l}\text { Yes, but with other type of agents (midwife, } \\
\text { nurse with technical education) }\end{array}$} & $10.04 \%$ \\
\hline \multicolumn{2}{|l|}{ No } & $10.14 \%$ \\
\hline \multicolumn{3}{|l|}{ Absences } \\
\hline \multirow{2}{*}{$\begin{array}{l}\text { Mean: 5.1061; } \\
\text { Max } 11\end{array}$} & CI $95 \%$ & $(4.905783-5.3065)$ \\
\hline & & Min 0 \\
\hline
\end{tabular}

In figure 1, frequency distribution of absences is showed 
Table 5. Analysis of antenatal consultations with two part model

\begin{tabular}{|c|c|c|c|c|}
\hline \multirow[b]{2}{*}{ Variables } & \multicolumn{2}{|c|}{$\begin{array}{l}\text { Logistic regression on } \\
\text { probability of at least } \\
\text { consultation (Logit) }\end{array}$} & \multicolumn{2}{|c|}{$\begin{array}{l}\text { OLS analysis of consultations } \\
\text { given at least one consultation }\end{array}$} \\
\hline & \multicolumn{2}{|c|}{$\begin{array}{c}\text { Coefficient } \\
\text { (Standard Errors) }\end{array}$} & \multicolumn{2}{|c|}{$\begin{array}{c}\text { Coefficient } \\
\text { (Robust Standard Errors) }\end{array}$} \\
\hline Constant & -1.5479 & $(1.4105)$ & $7.5464 * * *$ & $(1.2318)$ \\
\hline Caribbean region & 0.0336 & $(0.4359)$ & -0.2987 & $(0.3204)$ \\
\hline Eastern region & 0.4917 & $(0.4795)$ & -0.1902 & $(0.3044)$ \\
\hline Central region & -0.6648 & $(0.4247)$ & -0.2120 & $(0.2899)$ \\
\hline Pacific region & $-0.9592 * *$ & $(0.4356)$ & -0.4576 & $(0.3235)$ \\
\hline Orinoco river and Amazonas regions & 0.0514 & $(0.4576)$ & -0.2378 & $(0.4197)$ \\
\hline Urban & -0.1750 & $(0.2701)$ & -0.0370 & $(0.2831)$ \\
\hline Time of residence & -0.0060 & $(0.0069)$ & 0.0024 & $(0.0080)$ \\
\hline People living in the household & $-0.3282 *$ & $(0.1855)$ & -0.0953 & $(0.1368)$ \\
\hline People living in household ${ }^{\wedge} 2$ & $0.0267^{*}$ & $(0.0155)$ & 0.0118 & $(0.0098)$ \\
\hline Logarithm of wealth & $0.9600^{* * *}$ & $(0.3141)$ & $-0.5986^{* *}$ & $(0.2980)$ \\
\hline EPS & 0.5084 & $(0.3604)$ & $-0.8264 * * *$ & $(0.2524)$ \\
\hline ARS & $0.4707^{* *}$ & $(0.2325)$ & -0.2686 & $(0.2374)$ \\
\hline Demand & - & - & $-0.7527 * * *$ & $(0.2909)$ \\
\hline Supply & - & - & $-0.6021^{*}$ & $(0.3405)$ \\
\hline Stable union & $0.6287^{* *}$ & $(0.2472)$ & $-0.4354 * *$ & $(0.2042)$ \\
\hline Mother's years of education & $0.2137 * *$ & $(0.1037)$ & $-0.2332 * *$ & $(0.1069)$ \\
\hline Mother's years of education^2 & $-0.0120^{*}$ & $(0.0067)$ & $0.0120 * *$ & $(0.0058)$ \\
\hline Father's years of education & 0.0123 & $(0.0251)$ & -0.0075 & $(0.0205)$ \\
\hline Literacy & 0.0943 & $(0.3308)$ & 0.4714 & $(0.4279)$ \\
\hline Non-Willingness & -0.0007 & $(0.0018)$ & $0.0026^{*}$ & $(0.0014)$ \\
\hline Age of delivery & $0.1370^{*}$ & $(0.0737)$ & -0.0301 & $(0.0639)$ \\
\hline Age of delivery ${ }^{\wedge} 2$ & -0.0011 & $(0.0011)$ & -0.0001 & $(0.0009)$ \\
\hline Time of pregnancy loss & 0.0014 & $(0.0012)$ & $0.0017 *$ & $(0.0009)$ \\
\hline Multiple pregnancy & 1.4798 & $(1.0464)$ & $-2.3224 * * *$ & $(0.8585)$ \\
\hline Number of children & $-0.1554 * *$ & $(0.0768)$ & $0.2162 * * *$ & $(0.0703)$ \\
\hline Number of observations & 1253 & & 965 & \\
\hline$F($ Prob $>F)$ & $5.43(<0.00$ & & & \\
\hline $\mathbf{R}^{2}$ & & & 0.1896 & \\
\hline
\end{tabular}


Figure 1. Distribution of absences to antenatal care visits

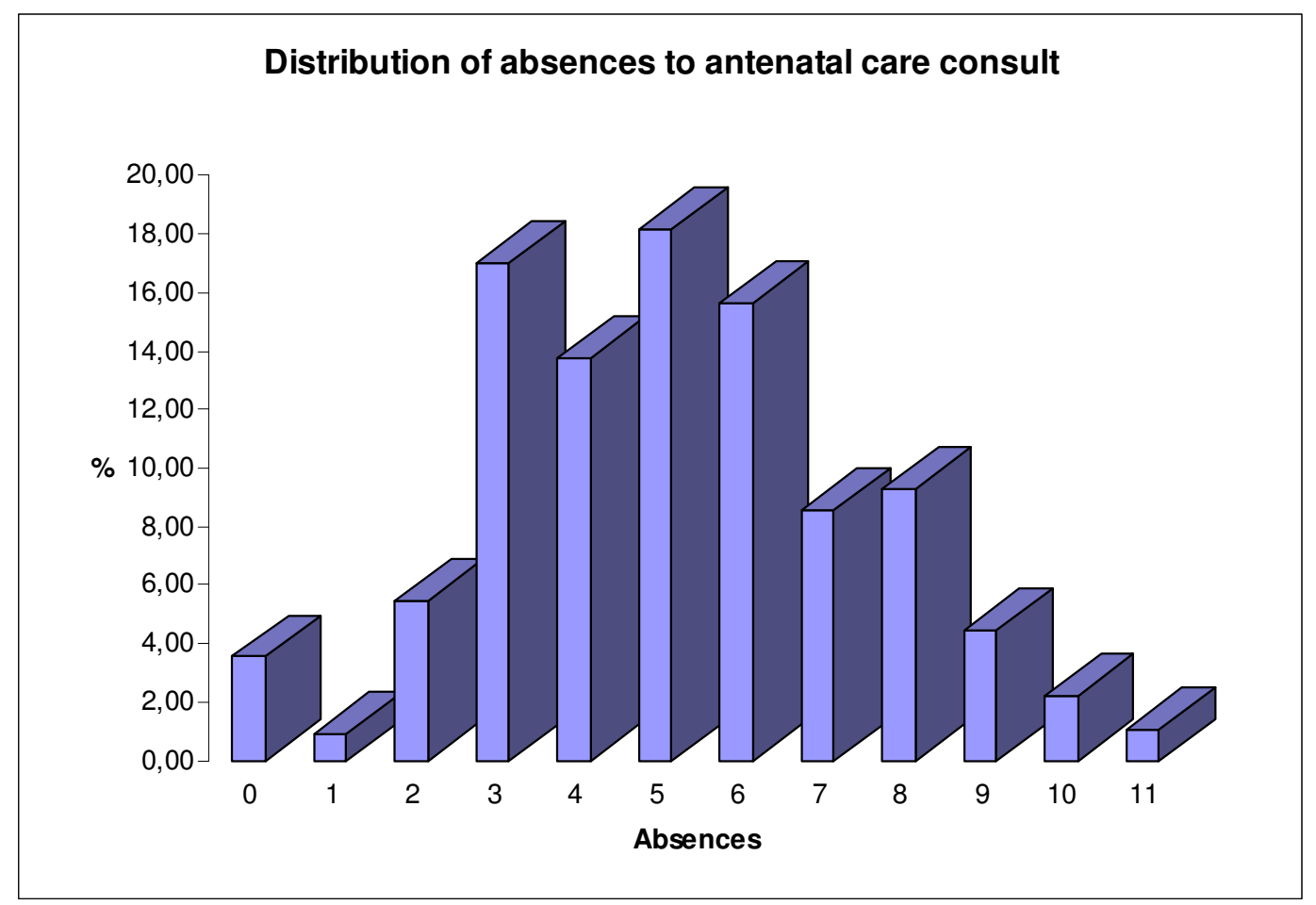

